\title{
Raynaud phenomenon and mortality: $20+$ years of follow-up of the Charleston Heart Study cohort
}

This article was published in the following Dove Press journal:

Clinical Epidemiology

3 February 2015

Number of times this article has been viewed

Paul J Nietert ${ }^{\prime}$

Stephanie R Shaftman'

Richard M Silver ${ }^{2}$

Bethany J Wolf'

Brent M Egan ${ }^{3}$

Kelly J Hunt ${ }^{\prime}$

Edwin A Smith ${ }^{2}$

'Department of Public Health Sciences, Medical University of South Carolina, Charleston, SC, USA; ${ }^{2}$ Department of Medicine, Division of Rheumatology and Immunology, Medical University of South Carolina, Charleston, SC, USA; ${ }^{3}$ Greenville Health System, Care Coordination Institute, Greenville, SC, USA
Correspondence: Paul J Nietert 135 Cannon Street, Suite 303, MSC 835, Medical University of South Carolina, Charleston, SC, USA

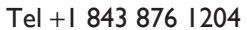

Fax + I 843876 II 26

Email nieterpj@musc.edu
Background: Raynaud phenomenon (RP) is a temporary vasoconstrictive condition that often manifests itself in the fingers in response to cold or stress. It often co-occurs with certain chronic diseases that impact mortality. Our objective was to determine whether RP has any independent association with survival.

Methods: From 1987-1989, a total of 830 participants of the Charleston Heart Study cohort completed an in-person RP screening questionnaire. Two definitions of RP were used: a broad definition that included both blanching (pallor) and cyanotic color changes and a narrow definition that included only blanching. All-cause and cardiovascular disease (CVD) mortality were compared between subjects with and without RP using race-specific survival models that adjusted for age, sex, baseline CVD, and 10-year risk of coronary heart disease.

Results: Using the narrow RP definition, we identified a significant interaction between older age and the presence of RP on all-cause mortality. In the broad RP definition model, the presence of RP was not associated with CVD mortality among blacks; however, among whites, the presence of RP was associated with a 1.6-fold increase in the hazard associated with CVD-related death (hazard ratio: $1.55,95 \%$ confidence interval: $1.10-2.20, P=0.013$ ).

Conclusion: RP was independently associated with mortality among older adults in our cohort. Among whites, RP was associated with increased CVD-related death. It is possible that RP may be a sign of undiagnosed vascular disease.

Keywords: Raynaud disease, cohort studies, cardiovascular diseases, survival analysis

\section{Introduction}

Raynaud phenomenon (RP) is a temporary vasoconstrictive condition that occurs in response to cold or stress. Usually, RP is characterized by pallor (or "blanching"), typically of the fingers or toes, although these changes are often accompanied by subsequent cyanosis. ${ }^{1}$ RP may occur as a primary condition or secondary to chronic diseases that impact mortality, ${ }^{1}$ including rheumatologic illnesses, and it is also found in conjunction with hand-arm vibration syndrome (seen mostly in men), certain drugs (beta blockers, ergotamine), chemicals, and other occupational exposures (vinyl chloride) as well as conditions such as migraine, diabetes, carpal tunnel syndrome, hypothyroidism, and frostbite. $^{2-5}$ Although primary RP is generally deemed to be relatively benign, there has been no prior long-term follow-up study determining whether RP has any independent association with mortality. We addressed this research question in the context of a long-term epidemiologic cohort study.

It is well-known that blacks have a greater risk of connective tissue diseases such as systemic sclerosis and systemic lupus erythematosus, as well as greater morbidity and 
mortality from these conditions than whites. ${ }^{6-11}$ Blacks also have higher mortality rates of cardiovascular disease (CVD) than whites. ${ }^{12}$ Thus, while we were interested in determining whether RP had any independent association with mortality, we were also interested in determining whether any such effects were more pronounced in blacks than whites. Racial differences in the expression of RP (primary or secondary) have not been examined comprehensively except for one study of an inner-city black population. ${ }^{6}$ Investigators found that their cohort had an RP prevalence rate of $3.8 \%$, similar to other racial groups around the country and world, ${ }^{13-17}$ and they identified a possible causal relationship between underlying CVD and the development of RP. ${ }^{6}$

Several different techniques are used to diagnose RP, including patient-reported symptoms, physical exams to assess the presence of lesions and deformities, and tests such as laser Doppler flowmetry, digital plethysmography, laser Doppler perfusion imaging, color Doppler ultrasonography, and cold simulation tests. ${ }^{18-21}$ In 1988, Maricq and Weinrich developed a method of diagnosing RP using color charts and four simple criteria. ${ }^{22}$ In their sample, this method was highly sensitive (90\%) and specific (100\%), but only considers blanching to be indicative of RP; cyanosis was omitted since its inclusion may lower the specificity of their definition. ${ }^{22}$ This technique was used, for example, in a population-based study of the incidence and natural history of $\mathrm{RP}^{23}$ and has been incorporated into recent consensus diagnostic criteria. ${ }^{24}$ Other researchers argue, however, that cyanosis is directly related to RP and cannot be ignored ${ }^{25}$ and that a broader definition of RP be used, one that allows for the occurrence of whitening and cyanosis. ${ }^{26}$

The current study was based on data from participants of the Charleston Heart Study (CHS), a population-based cohort study that began enrolling subjects in 1960. The original geographicbased sampling strategy was described in an article by Boyle in $1970 .{ }^{27}$ The primary purpose of the original cohort study was to better understand the natural aging process in the white and black populations, with a focus on CVD and its associated risk factors. One of the follow-up sub-studies, conducted in 1987, contained a detailed in-person RP questionnaire developed by a researcher (Hildegard Maricq, $\mathrm{MD}$ ), whose primary expertise was in finding ways to best identify and manage RP.

A number of studies have examined RP in the general population, ${ }^{6,17,28,29}$ but none have examined what, if any, association exists between a diagnosis of RP and the timing of all-cause or cardiovascular mortality. This study aims to understand these relationships in a predominantly elderly population with no known connective tissue disease.

\section{Methods}

\section{Study subjects}

From 1987 to 1989, all surviving members of the CHS cohort were contacted and asked to consent to an in-person follow-up interview about their disease history, RP symptoms, and current medications. Blood samples were also obtained, and a variety of laboratory tests relevant to CVD were conducted. Subjects were followed until death or loss-to-follow-up. The disease history and current medications were obtained through interview with a cardiologist. The study was approved by the Institutional Review Board of the Medical University of South Carolina.

A total of 1,072 people consented and participated in at least one component of the follow-up interview/exam ( $~ 93 \%$ response rate among members believed to be alive in 1987). Of these participants, 830 (77\%) of the 1,072 subjects completed the RP screening questionnaire, designed by a physician with expertise in researching and treating RP (Hildegard Maricq, MD). For each subject, his/her baseline was the date on which their interview and exam occurred.

\section{Study measures}

Subjects were classified as having RP or not having RP, based upon certain RP classification criteria. Because of the controversy about how RP should be defined, two definitions of RP were used for these analyses. The first definition, referred to as the "narrow" definition, was adapted from Maricq and Weinrich, ${ }^{22}$ based on color charts used during the interview/exam. This definition required subjects to have reported "blanching" or whitening of their fingers and did not depend on whether the subject experienced any cyanosis of their fingers/hands. In the original manuscript by Maricq and Weinrich discussing the RP questionnaire, this definition was shown to have a sensitivity of $90 \%$ and a specificity of $100 \%$ when compared to a clinician-based reference standard. ${ }^{22}$ In addition to this narrow definition, we constructed a "broad" RP definition, which allowed for patients to be classified as having RP if they met the narrow definition, or if they indicated that their fingertips and/or hands ever became cyanotic, again using color charts as a comparison. Specifics of these definitions are provided in the Supplementary materials. It should be noted that there are recently published diagnostic criteria for RP. ${ }^{24}$ Our RP questionnaire, however, was developed many years prior to these recent criteria and did not address each of the items in the new criteria; thus, the new criteria could not be adapted for the current analysis. Also, the RP questionnaire did not include questions about the frequency or duration of the RP symptoms. 
Subjects' vital status was obtained in several ways. A search (submitted on November 29, 2011) of the National Death Index (NDI) databases that used subject identifiers including first and last name, date of birth, and social security number yielded vital status information that was considered up-to-date through December 31, 2009. For deaths identified through this process, dates of death and up to 20 causes of death (coded using International Classification of Disease [ICD] Codes $-\mathrm{v} 8,9$, or 10) were obtained. Subjects who were not found in any of the NDI searches were presumed alive as of their last date of contact and treated as censored as of that date in the survival analyses. The primary study outcomes were time to death (all-cause) and time to CVD-related death. CVD-related death was defined as death from coronary heart disease (CHD) and/or stroke, as indicated on any of a subject's NDI cause of death codes, based on ICD Ninth (ICD-9) and Tenth Editions (ICD-10). For ICD-9 codes, CVD death was defined by codes 390-448 (major CVDs), while for ICD-10 codes, CVD death was defined by codes I00-I78 (major CVDs); this method is consistent with the way the Centers for Disease Control and Prevention define CVD mortality. ${ }^{30,31}$ In the analysis of CVD-related mortality, subjects with deaths from other causes were treated as censored observations.

In our analyses, we controlled for several potential confounding variables, including demographics (age at interview/exam, sex, race), CVD status at interview/exam, and future risk of CHD. CVD status at the time of their RP interview/exam was determined based on subjects selfreporting a physician diagnosis of one or more of the following medical conditions: stroke, myocardial infarction, angina pectoris, heart failure, or peripheral vascular disease (PVD). Future risk of CHD was defined using Framingham risk scoring. ${ }^{32} \mathrm{CHD}$ risk scores ranged from $1 \%$ to $30 \%$ and were treated as continuous covariates in all analyses. We also examined whether RP status was associated with baseline history of rheumatologic disease (systemic sclerosis, rheumatoid arthritis, thyroid disease, or other rheumatologic disease) and current medications at time of RP interview (beta blockers, calcium channel blockers, other antihypertensive agents, cholesterol-lowering agents, and aspirin).

\section{Statistical analysis}

Descriptive statistics were used to characterize subjects with and without RP at baseline. Unadjusted differences between groups were assessed using independent sample $t$-tests or chi-square tests, as appropriate. RP status was known on all subjects; however, two variables (total cholesterol and high density lipoprotein cholesterol) had missing values on a small proportion $(-5 \%)$ of subjects. Rubin's ${ }^{33}$ multiple imputation methods were used to allow for the entire sample to be included in the analyses.

All-cause and CVD mortality was compared between subjects with and without RP using Cox proportional hazards models. The primary independent variable was RP status; baseline age (as of their RP assessment), sex, race, baseline CVD status, and 10-year CHD risk served as covariates. The proportionality assumption was confirmed by noting that the inclusion of $\mathrm{RP} \times \log$ (survival time) interactions in each of our models was not statistically significant $(P>0.05) .{ }^{34} \mathrm{~A}$ Cox model was constructed for the entire study population, followed by race-specific analyses, which were pre-specified because of the potential for effect modification. The two-way interaction between RP status and each covariate was also assessed and included in the final model when statistically significant $(P<0.05)$. Kaplan-Meier survival curves were generated to depict the unadjusted findings, and the Cox model hazard ratios (HRs) and their 95\% confidence intervals (CIs) were used to summarize the covariate-adjusted findings. Sensitivity analyses were performed to examine the impact of excluding the $8 \%$ of study subjects with a history of PVD at the time of RP questionnaire administration. All analyses were conducted using SAS (v9.3; SAS Institute Inc., Cary, NC, USA). With a total sample size of $n=830$, we had $80 \%$ power to detect RP-specific HRs of 1.54 and 1.29 using the narrow and broad definitions, respectively. With $\mathrm{n}=303$ blacks included, we had $80 \%$ power to detect HRs of 2.09 and 1.52 using the narrow and broad definitions, respectively, and with $n=527$ whites included, we had $80 \%$ power to detect HRs of 1.69 and 1.38 .

\section{Results}

A total of 830 subjects completed the interview and RP questionnaire. These subjects were more likely to be male than the $n=242$ subjects who did not complete the interview and RP questionnaire: (completers, $44.9 \%$ male; non-completers, $34.3 \%$ male; $P=0.003$ ), but their racial distribution was similar (completers, $63.5 \%$ white; noncompleters, $62.8 \%$ white; $P=0.85$ ). Of the 830 subjects included in the analyses, $40(4.8 \%)$ met the criteria for RP under the narrow definition, and 139 (16.7\%) met the criteria for RP under the broad definition. None of the subjects interviewed reported having been diagnosed with systemic sclerosis or any other rheumatologic disease, with the exception of 20 subjects reporting having rheumatoid arthritis. Demographic and clinical characteristics of the study subjects, stratified by RP status, are presented in 
Table I Demographic and clinical characteristics of study subjects with and without RP (using narrow and broad definitions)

\begin{tabular}{|c|c|c|c|c|}
\hline \multirow[t]{2}{*}{ Characteristic } & \multicolumn{2}{|c|}{$\begin{array}{l}\text { RP status: narrow } \\
\text { definition }\end{array}$} & \multicolumn{2}{|c|}{$\begin{array}{l}\text { RP status: broad } \\
\text { definition }\end{array}$} \\
\hline & $\begin{array}{l}\text { Absent } \\
(n=790)\end{array}$ & $\begin{array}{l}\text { Present } \\
(n=40)\end{array}$ & $\begin{array}{l}\text { Absent } \\
(n=691)\end{array}$ & $\begin{array}{l}\text { Present } \\
(n=139)\end{array}$ \\
\hline Sex: (\% male) & $44.7 \%$ & $50.0 \%$ & $44.4 \%$ & $47.5 \%$ \\
\hline Race: (\% white) & $63.3 \%$ & $67.5 \%$ & $63.5 \%$ & $63.3 \%$ \\
\hline \multirow[t]{2}{*}{ Age: mean (SD), years } & 71.7 & 72.0 & 71.6 & 72.4 \\
\hline & $(7.6)$ & (6.6) & $(7.5)$ & $(7.6)$ \\
\hline $\begin{array}{l}\text { Smoking status: } \\
\text { (\% current) }\end{array}$ & $16.1 \%$ & $7.5 \%$ & $16.6 \%$ & $10.8 \%$ \\
\hline Total cholesterol: & 236.2 & 227.9 & 236.5 & 232.2 \\
\hline mean (SD), mg/dL & $(45.4)$ & $(8 I .2)$ & $(45.9)$ & $(55.5)$ \\
\hline HDL cholesterol: & 49.8 & 52.3 & 49.4 & 52.3 \\
\hline mean (SD), mg/dL & $(16.1)$ & $(14.5)$ & $(15.5)$ & $(17.8)$ \\
\hline Systolic blood pressure: & 146.6 & 147.3 & 146.4 & 147.9 \\
\hline mean (SD), mmHg & $(20.7)$ & $(22.1)$ & $(20.5)$ & $(22.1)$ \\
\hline Diastolic blood pressure: & 83.5 & 83.7 & 83.5 & 83.4 \\
\hline mean (SD), mmHg & $(I I .7)$ & $(I I .6)$ & $(11.7)$ & (II.6) \\
\hline 10-year CHD risk: & $15.4 \%$ & $14.6 \%$ & $15.4 \%$ & $15.2 \%$ \\
\hline mean $(S D)$ & $(8.4 \%)$ & $(7.4 \%)$ & $(8.4 \%)$ & $(8.0 \%)$ \\
\hline \multicolumn{5}{|l|}{ Baseline history of CVD } \\
\hline $\begin{array}{l}\text { History of any } \\
\text { CVD (\%) }\end{array}$ & $28.7 \%$ & $35.0 \%$ & $27.1 \%$ & $38.9 \%^{\dagger}$ \\
\hline History of stroke (\%) & $6.5 \%$ & $2.5 \%$ & $6.5 \%$ & $5.0 \%$ \\
\hline History of MI (\%) & $10.6 \%$ & $15.0 \%$ & $10.4 \%$ & $13.0 \%$ \\
\hline History of angina (\%) & $12.4 \%$ & $25.0 \% *$ & $11.3 \%$ & $21.6 \%^{\dagger}$ \\
\hline $\begin{array}{l}\text { History of heart } \\
\text { failure (\%) }\end{array}$ & $4.1 \%$ & $10.0 \%$ & $3.8 \%$ & $7.2 \%$ \\
\hline History of PVD (\%) & $8.0 \%$ & $7.5 \%$ & $7.2 \%$ & $1 \mathrm{I} .5 \%$ \\
\hline \multicolumn{5}{|c|}{ Baseline history of rheumatologic disease } \\
\hline Systemic sclerosis & $0.0 \%$ & $0.0 \%$ & $0.0 \%$ & $0.0 \%$ \\
\hline Rheumatoid arthritis & $2.3 \%$ & $5.0 \%$ & $2.5 \%$ & $2.2 \%$ \\
\hline Thyroid disease & $3.8 \%$ & $0.0 \%$ & $3.9 \%$ & $2.2 \%$ \\
\hline $\begin{array}{l}\text { Other rheumatologic } \\
\text { disease }\end{array}$ & $0.0 \%$ & $0.0 \%$ & $0.0 \%$ & $0.0 \%$ \\
\hline \multicolumn{5}{|c|}{ Medication at time of RP interview } \\
\hline Beta blocker & $12.4 \%$ & $30.0 \% *$ & $12.5 \%$ & $17.3 \%$ \\
\hline $\begin{array}{l}\text { Calcium channel } \\
\text { blocker }\end{array}$ & $8.6 \%$ & $5.0 \%$ & $9.0 \%$ & $5.8 \%$ \\
\hline $\begin{array}{l}\text { Other antihypertensive } \\
\text { agent }\end{array}$ & $12.8 \%$ & $7.5 \%$ & $13.5 \%$ & $7.9 \%$ \\
\hline $\begin{array}{l}\text { Cholesterol-lowering } \\
\text { agent }\end{array}$ & $1.0 \%$ & $0.0 \%$ & $1.2 \%$ & $0.0 \%$ \\
\hline Aspirin & $27.0 \%$ & $30.0 \%$ & $25.5 \%$ & $35.3 \% *$ \\
\hline $\begin{array}{l}\text { Finger/hand blanching: } \\
\text { (\% present) }\end{array}$ & $6.8 \%$ & $100.0 \% *$ & $5.2 \%$ & $41.7 \%^{\dagger}$ \\
\hline $\begin{array}{l}\text { Finger/hand cyanosis: } \\
\text { (\% present) }\end{array}$ & $12.6 \%$ & $35.0 \% *$ & $0.0 \%$ & $81.3 \%^{\dagger}$ \\
\hline
\end{tabular}

Notes: $* P<0.05$ when compared to subjects with RP absent (narrow definition); ${ }^{t} P<0.05$ when compared to subjects with RP absent (broad definition).

Abbreviations: CHD, coronary heart disease; CVD, cardiovascular disease; HDL, high density lipoprotein; MI, myocardial infarction; PVD, peripheral vascular disease; RP, Raynaud's phenomenon; SD, standard deviation.

Table 1. Under the narrow RP definition, history of angina was significantly more common among subjects with RP compared to those without RP. Under the broad RP definition, history of CVD and history of angina were significantly more common among subjects with RP compared to those without RP. RP status was not associated with baseline history of rheumatologic disease. Under the narrow definition, subjects with RP were more likely than subjects without RP to be on beta blockers (30.0\% vs $12.4 \%$, $P<0.05)$, and under the broad definition, subjects with RP were more likely to report taking aspirin regularly $(35.3 \%$ vs $25.5 \%, P<0.05)$.

Under both RP definitions, median survival time was somewhat shorter for white subjects with RP present at their baseline interview compared to white subjects without RP present. Specifically, under the narrow definition, the median survival time was 10.7 years (95\% CI: 9.9-11.9 years) for white subjects without RP, compared to 7.0 years $(95 \% \mathrm{CI}$ : 5.6-13.2 years) for white subjects with RP. Among blacks, there was no evidence that RP had any impact on median survival time under the narrow RP definition (RP absent: 10.8 years vs RP present: 11.1 years). Under the broad definition, the median survival time was 11.0 years (95\% CI: 10.0-12.1 years) for white subjects without RP, compared to 8.1 years (95\% CI: 6.0-11.8 years) for white subjects with RP. Among blacks, there was no evidence that RP had any impact on survival under the broad RP definition (RP absent: 10.9 years vs RP present: 9.9 years). $P$-values were not reported for these median differences, since these analyses did not consider the potential confounding variables.

The results of the multivariable Cox proportional hazards models predicting all-cause mortality are summarized in Table 2. In the narrow definition model, no significant two-way interactions between RP and any of the covariates were identified, with the exception being a moderately significant $(P=0.034)$ interaction between $\mathrm{RP}$ and age as of the interview/exam date. In that model, the association between RP and all-cause mortality was greater among older subjects versus younger subjects. For example, the model's predicted HR for 65-year-olds with RP was 0.78 (95\% CI: 0.47-1.31), while the HR for 85-year-olds was 2.42 (95\% CI: 1.15-5.08). In terms of individual risk, the model suggested that for 65-year-olds with RP in our cohort, the average 5-year survival probability was $90.3 \%$ compared to $87.8 \%$ for subjects without RP, while for 85 -year-olds with RP, the average 5-year survival probability was $25.4 \%$ compared to $56.7 \%$ for subjects without RP.

Table 2 also illustrates that RP was not significantly $(P>0.05)$ associated with all-cause mortality in the broad RP definition model for the entire sample, or for either race group. Results of these models also emphasize the significant $(P<0.05)$ independent associations between mortality and older age, male sex, and the presence of CVD. After adjusting for all the variables included in the models, the 10-year CHD 
Table 2 Results of the Cox proportional hazards models predicting all-cause mortality, for the entire sample and stratified by race

\begin{tabular}{|c|c|c|c|c|}
\hline \multirow[t]{2}{*}{ Characteristic } & \multicolumn{2}{|c|}{$\begin{array}{l}\text { Narrow } \\
\text { definition model }\end{array}$} & \multicolumn{2}{|c|}{$\begin{array}{l}\text { Broad } \\
\text { definition model }\end{array}$} \\
\hline & HR & $95 \% \mathrm{Cl}$ & HR & $95 \% \mathrm{Cl}$ \\
\hline \multicolumn{5}{|l|}{ Entire sample $(\mathrm{n}=830)$} \\
\hline RP present & $0.02 *$ & $(0.00-0.88)$ & 1.15 & $(0.94-1.40)$ \\
\hline Age & $1.07 *$ & $(1.06-1.08)$ & $1.07 *$ & $(1.06-1.08)$ \\
\hline RP present $\times$ age & $1.06 *$ & $(1.00-1.11)$ & - & - \\
\hline Male sex & I.42* & $(1.17-1.73)$ & $1.40 *$ & $(1.15-1.70)$ \\
\hline White race & 1.01 & $(0.86-1.19)$ & 1.01 & $(0.86-1.19)$ \\
\hline CVD present & I.45* & $(|.22-| .7 \mid)$ & $1.40 *$ & $(1.19-1.66)$ \\
\hline 10-year CHD risk & 1.01 & $(1.00-1.02)$ & 1.01 & $(1.00-1.02)$ \\
\hline \multicolumn{5}{|l|}{ Blacks $(n=303)$} \\
\hline RP present & 1.09 & $(0.55-2.14)$ & 1.05 & $(0.74-1.49)$ \\
\hline Age & $1.07 *$ & (I.05-1.09) & $1.07 *$ & $(1.05-1.09)$ \\
\hline Male sex & 1.05 & $(0.76-1.45)$ & 1.06 & $(0.77-1.46)$ \\
\hline CVD present & $1.45^{*}$ & $(1.10-1.92)$ & $1.45^{*}$ & $(1.10-1.91)$ \\
\hline I0-year CHD risk & $\mathrm{I} .0 \mathrm{I}$ & $(0.99-1.03)$ & 1.01 & $(0.99-1.03)$ \\
\hline \multicolumn{5}{|l|}{ Whites $(n=527)$} \\
\hline RP present & 1.10 & $(0.72-1.68)$ & 1.16 & $(0.90-1.49)$ \\
\hline Age & $1.07 *$ & $(1.06-1.09)$ & $1.07 *$ & $(1.06-1.09)$ \\
\hline Male sex & I.7I* & $(1.33-2.20)$ & I.68* & $(1.30-2.17)$ \\
\hline CVD present & $1.39 *$ & $(|| 2-.|.7|)$ & $1.36 *$ & $(1.10-1.68)$ \\
\hline 10-year CHD risk & 1.01 & $(0.99-1.02)$ & 1.01 & $(0.99-1.02)$ \\
\hline
\end{tabular}

Note: $* P<0.05$ by multivariable Cox proportional hazards modeling.

Abbreviations: CHD, coronary heart disease; $\mathrm{Cl}$, confidence interval; CVD, cardiovascular disease; HR, hazard ratio; RP, Raynaud's phenomenon.

risk score was not significantly associated with all-cause mortality.

Of the 673 subjects who died during the study followup, cause of death was obtained on 629 (93.4\%). Among the subjects with a cause of death listed, $51.4 \%$ were noted as having died due, in part, to CVD. Results of the multivariable survival models predicting CVD mortality are summarized in Table 3. In the narrow RP definition model, the presence of RP was not significantly associated with CVD mortality. Similarly, in the broad RP definition model, the presence of RP was not significantly associated with CVD mortality in the entire sample or among blacks. However, among whites, the presence of RP was associated with a 1.6-fold increase in the hazard associated with CVD-related death (HR: 1.55, 95\% CI: 1.10-2.20, $P=0.013)$. Figure 1 illustrates the relationship between RP (broad definition) and CVD mortality, separately for whites (Figure 1A) and blacks (Figure 1B). No significant two-way interactions involving RP and the covariates were identified.

When subjects with a history of PVD were excluded from the all-cause and CVD mortality analyses, the relative strength of the associations between RP and mortality remained largely unchanged. In fact, in almost all of
Table 3 Results of the Cox proportional hazards models predicting CVD mortality, for the entire sample and stratified by race

\begin{tabular}{|c|c|c|c|c|}
\hline \multirow[t]{2}{*}{ Characteristic } & \multicolumn{2}{|c|}{$\begin{array}{l}\text { Narrow } \\
\text { definition model }\end{array}$} & \multicolumn{2}{|c|}{$\begin{array}{l}\text { Broad } \\
\text { definition model }\end{array}$} \\
\hline & HR & $95 \% \mathrm{Cl}$ & HR & $95 \% \mathrm{Cl}$ \\
\hline \multicolumn{5}{|l|}{ Entire sample $(n=830)$} \\
\hline RP present & 0.84 & $(0.47-1.5 I)$ & 1.16 & $(0.87-1.53)$ \\
\hline Age & $1.08^{*}$ & $(1.06-1.10)$ & $1.08^{*}$ & $(1.06-1.10)$ \\
\hline Male sex & 1.30 & $(0.98-1.7 I)$ & 1.29 & $(0.98-1.70)$ \\
\hline White race & 0.86 & $(0.68-1.08)$ & 0.86 & $(0.68-1.08)$ \\
\hline CVD present & $1.61^{*}$ & $(1.28-2.04)$ & $1.60 *$ & (1.26-2.02) \\
\hline I0-year CHD risk & $1.02 *$ & $(1.00-1.04)$ & $1.02 *$ & $(1.00-1.04)$ \\
\hline \multicolumn{5}{|l|}{ Blacks $(n=303)$} \\
\hline RP present & 0.42 & $(0.10-1.71)$ & 0.65 & $(0.38-1.12)$ \\
\hline Age & $1.09 *$ & $(1.06-1.11)$ & $1.09 *$ & $(1.06-1.12)$ \\
\hline Male sex & 1.16 & $(0.74-1.80)$ & 1.06 & $(0.68-1.65)$ \\
\hline CVD present & 1.34 & $(0.91-1.95)$ & 1.36 & $(0.93-1.99)$ \\
\hline 10-year CHD risk & 1.02 & $(0.99-1.05)$ & 1.02 & $(0.99-1.05)$ \\
\hline \multicolumn{5}{|l|}{ Whites $(n=527)$} \\
\hline RP present & 1.04 & $(0.54-1.97)$ & $1.55^{*}$ & $(1.10-2.20)$ \\
\hline Age & $1.07^{*}$ & $(1.05-1.10)$ & $1.08^{*}$ & $(1.05-1.10)$ \\
\hline Male sex & $\mathrm{I} .4 \mathrm{I}$ & $(0.98-2.03)$ & 1.35 & $(0.94-1.95)$ \\
\hline CVD present & $1.82 *$ & $(1.35-2.45)$ & I.70* & $(1.26-2.30)$ \\
\hline I0-year CHD risk & 1.02 & $(0.99-1.04)$ & 1.02 & $(1.00-1.04)$ \\
\hline
\end{tabular}

Note: $* P<0.05$ by multivariable Cox proportional hazards modeling.

Abbreviations: $\mathrm{CHD}$, coronary heart disease; $\mathrm{Cl}$, confidence interval; CVD, cardiovascular disease; HR, hazard ratio; RP, Raynaud's phenomenon.

these models, the RP HRs tended to increase slightly when compared to the analyses that included subjects with PVD.

\section{Discussion}

In this study, we identified a potentially significant relationship between RP and all-cause mortality, with the association being stronger among older subjects with RP compared with younger subjects. Interestingly, RP was not significantly associated with CVD mortality in blacks; however, among whites using the broad RP definition, the presence of RP was associated with a 1.6-fold increase in the hazard associated with CVD-related death.

It is worthy to emphasize that these findings are associative in nature and do not necessarily imply that RP causes increased mortality risk; the underlying mechanisms by which RP could be associated with increased mortality risk remain unclear. In the present study it was found that, in addition to the association of RP with CVD-related death, RP was also associated with angina. Angina can be caused by coronary vasoconstriction (Prinzmetal's or variant angina) which may or may not be similar to the arterial vasoconstriction causing RP. It is possible that the fault intrinsic to the vessels is common between the digital arteries and the coronary arteries of patients with RP. This potential relationship has been 

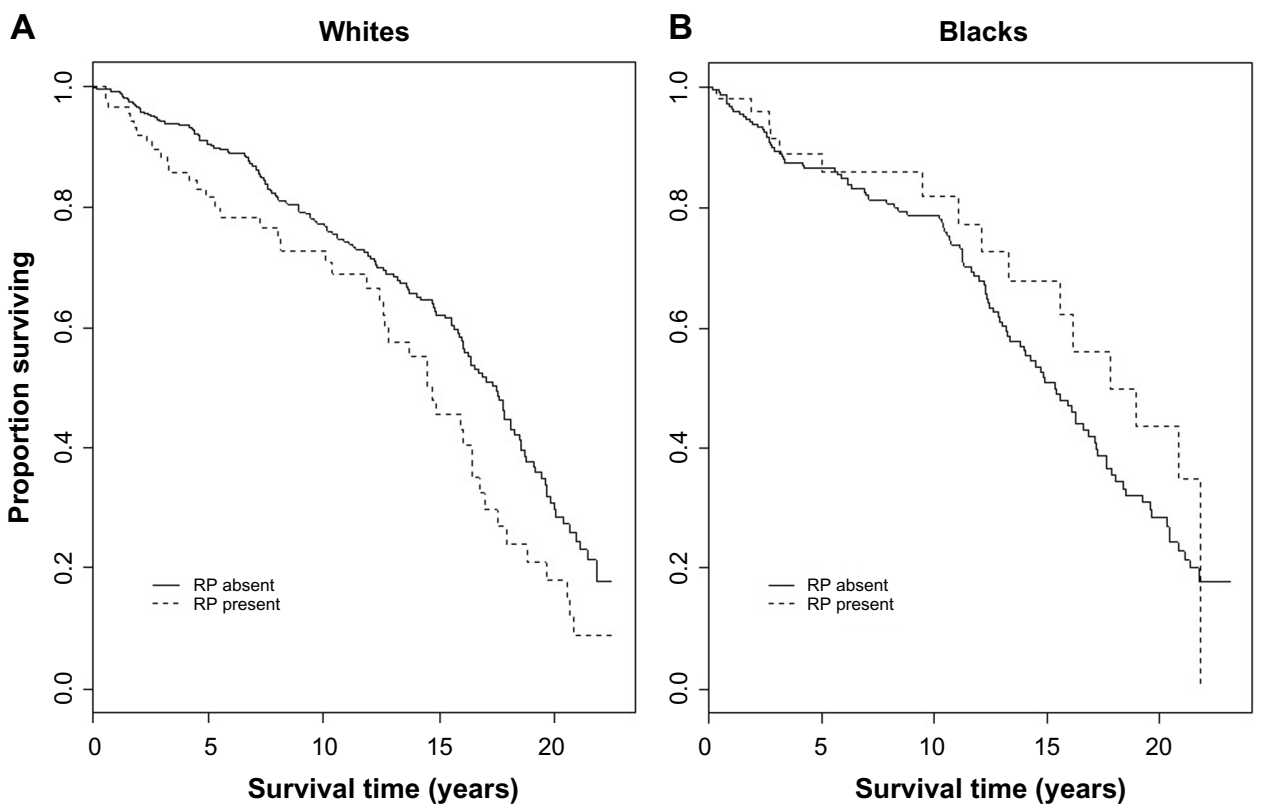

Figure I Kaplan-Meier curves reflecting cardiovascular disease-specific mortality rates among (A) white and (B) black participants with and without RP, using the broad RP definition.

Abbreviation: RP, Raynaud phenomenon.

described previously. ${ }^{35}$ Together, our findings indicate that RP may be a sign or precursor of undiagnosed vascular disease in some people. This theory is consistent with RP being the result of an intrinsic problem within the blood vessels and not a result of a systemic or humoral problem. ${ }^{36}$ For example, levels of neither epinephrine nor norepinephrine are elevated in RP sufferers, ${ }^{37,38}$ and it is possible to induce an RP episode in a digit that has its sympathetic nerve output blocked; ${ }^{26,39}$ facts that both allude to vascular disorder.

Strengths of this study include the relatively large numbers of subjects, two race groups being well-represented, use of a formalized RP assessment developed by a well-established expert RP researcher, and a lengthy follow-up period. Limitations include the lack of other race/ethnic groups and lack of more objective RP diagnostic testing, such as Laser Doppler flowmetry, digital plethysmography, laser Doppler perfusion imaging, or cold simulation tests. Compared to subjects without RP, subjects with RP were more likely to be taking beta blockers and less likely to be taking aspirin at baseline; however, it is difficult to know from this study whether RP may be a side effect of certain medications (as has been reported for beta blockers $)^{40}$ or whether subjects were prescribed these medications partially because they had RP (as may have been the case with aspirin). Additionally, our findings were not entirely consistent with each other; thus, studies involving larger cohorts of subjects with RP may be warranted.
The results of this study shed new light on RP, a relatively common but understudied condition. RP was independently associated with mortality among older adults in our cohort, and it was associated to some degree with CVD mortality among whites specifically. Physicians may wish to consider increasing the attention given to CVD prevention among their patients who report symptoms consistent with RP. Future studies may consider studying whether any interventions may reduce the risk of future CVD-related events among patients with RP.

\section{Acknowledgments}

This project was supported by grants from the National Center for Advancing Translational Sciences and from the National Institute for Arthritis and Musculoskeletal and Skin Diseases (UL1TR000062 and 1P60AR062755). The funding agencies had no role in the study design; in the collection, analysis, and interpretation of data; in the writing of the report; or in the decision to submit the article for publication.

We would also like to acknowledge Hildegard Maricq, MD, who developed the Raynaud phenomenon screening process and other Charleston Heart Study investigators (Edwin Boyle Jr, MD; S Hope Sandifer, MD; Peter C Gazes, MD; Julian E Keil, Dr PH; Susan E Sutherland, PhD; David Bachman, MD), and Anbesaw Selassie, PhD.

\section{Disclosure}

The authors report no conflicts of interest in this work. 


\section{References}

1. Brown S. Diagnosis and management of patients with Raynaud's phenomenon. Nurs Stand. 2012;26(46):41-46.

2. Herrick AL. The pathogenesis, diagnosis and treatment of Raynaud phenomenon. Nat Rev Rheumatol. 2012;8(8):469-479.

3. Boulbou MS, Gourgoulianis KI, Krommydas GC, et al. Diabetes mellitus vs Raynaud disease: different lung vascular bed disorders. Arch Med Res. 2002;33(6):531-535.

4. Wigley FM. Clinical practice. Raynaud's phenomenon. $N$ Engl J Med. 2002;347(13):1001-1008.

5. Maricq HR, Mcgregor AR, Diat F, et al. Major clinical diagnoses found among patients with Raynaud phenomenon from the general population. J Rheumatol. 1990;17(9):1171-1176.

6. Gelber AC, Wigley FM, Stallings RY, et al. Symptoms of Raynaud's phenomenon in an inner-city African-American community: prevalence and self-reported cardiovascular comorbidity. J Clin Epidemiol. 1999;52(5):441-446.

7. Fessel WJ. Systemic lupus erythematosus in the community. Incidence, prevalence, outcome, and first symptoms; the high prevalence in black women. Arch Intern Med. 1974;134(6):1027-1035.

8. Siegel M, Lee SL. The epidemiology of systemic lupus erythematosus. Semin Arthritis Rheum. 1973;3(1):1-54.

9. Anderson E, Nietert PJ, Kamen DL, Gilkeson GS. Ethnic disparities among patients with systemic lupus erythematosus in South Carolina. J Rheumatol. 2008;35(5):819-825.

10. Nietert PJ, Mitchell HC, Bolster MB, Shaftman SR, Tilley BC, Silver RM. Racial variation in clinical and immunological manifestations of systemic sclerosis. J Rheumatol. 2006;33(2):263-268.

11. Nietert PJ, Silver RM, Mitchell HC, Shaftman SR, Tilley BC. Demographic and clinical factors associated with in-hospital death among patients with systemic sclerosis. J Rheumatol. 2005;32(10): 1888-1892.

12. Kurian AK, Cardarelli KM. Racial and ethnic differences in cardiovascular disease risk factors: a systematic review. Ethn Dis. 2007;17(1): 143-152.

13. Maricq HR, Carpentier PH, Weinrich MC, et al. Geographic variation in the prevalence of Raynaud's phenomenon: a 5 region comparison. J Rheumatol. 1997;24(5):879-889.

14. Valter I, Maricq HR. Prevalence of Raynaud phenomenon in Tartu and Tartumaa, southern Estonia. Scand J Rheumatol. 1997;26(2): $117-124$

15. Maricq HR, Carpentier PH, Weinrich MC, et al. Geographic variation in the prevalence of Raynaud's phenomenon: Charleston, SC, USA, vs Tarentaise, Savoie, France. J Rheumatol. 1993;20(1):70-76.

16. Bartelink ML, Wollersheim H, van de Lisdonk E, Spruijt R, van Weel C. Prevalence of Raynaud's phenomenon. Neth J Med. 1992;41(3-4): 149-152.

17. Maricq HR, Weinrich MC, Keil JE, LeRoy EC. Prevalence of Raynaud phenomenon in the general population. A preliminary study by questionnaire. J Chronic Dis. 1986;39(6):423-427.

18. Goundry B, Bell L, Langtree M, Moorthy A. Diagnosis and management of Raynaud's phenomenon. BMJ. 2012;344:e289.

19. Rosato E, Borghese F, Pisarri S, Salsano F. Laser Doppler perfusion imaging is useful in the study of Raynaud's phenomenon and improves the capillaroscopic diagnosis. J Rheumatol. 2009;36(10): 2257-2263.

20. Cherkas LF, Carter L, Spector TD, Howell KJ, Black CM, MacGregor AJ. Use of thermographic criteria to identify Raynaud's phenomenon in a population setting. J Rheumatol. 2003;30(4):720-722.
21. Schmidt WA, Krause A, Schicke B, Wernicke D. Color Doppler ultrasonography of hand and finger arteries to differentiate primary from secondary forms of Raynaud's phenomenon. J Rheumatol. 2008;35(8): 1591-1598.

22. Maricq HR, Weinrich MC. Diagnosis of Raynaud's phenomenon assisted by color charts. J Rheumatol. 1988;15(3):454-459.

23. Suter LG, Murabito JM, Felson DT, Fraenkel L. The incidence and natural history of Raynaud's phenomenon in the community. Arthritis Rheum. 2005;52(4):1259-1263.

24. Maverakis E, Patel F, Kronenberg DG, et al. International consensus criteria for the diagnosis of Raynaud's phenomenon. J Autoimmun. 2014;48-49:60-65.

25. Prete M, Fatone MC, Favoino E, Perosa F. Raynaud's phenomenon: from molecular pathogenesis to therapy. Autoimmun Rev. 2014;13(6): 655-667.

26. Engelhart M. The effect of sympathetic blockade and cooling in Raynaud's phenomenon. Clin Physiol. 1990;10(2):131-136.

27. Boyle E Jr. Biological patterns in hypertension by race, sex, body weight, and skin color. JAMA. 1970;213(10):1637-1643.

28. Maricq HR. Epidémiologie du phénomène de Raynaud dans la population générale [Epidemiology of Raynaud's phenomenon in the general population]. Vasa Suppl. 1989;27:15-17. French.

29. Maricq HR, Weinrich MC, Keil JE, et al. Prevalence of scleroderma spectrum disorders in the general population of South Carolina. Arthritis Rheum. 1989;32(8):998-1006.

30. Hoyert DL, Xu JQ. Deaths: Preliminary data for 2011. National Vital Statistics Reports. Vol 61. Hyattsville, MD: National Center for Health Statistics; 2012.

31. Major cardiovascular disease (CVD) during 1997-1999 and major CVD hospital discharge rates in 1997 among women with diabetes - United States. Vol 50. Atlanta, GA: Centers for Disease Control and Prevention; 2001:948-954.

32. National Cholesterol Education Program (NCEP) Expert Panel on Detection, Evaluation, and Treatment of High Blood Cholesterol in Adults (Adult Treatment Panel III). Third Report of the National Cholesterol Education Program (NCEP) Expert Panel on Detection, Evaluation, and Treatment of High Blood Cholesterol in Adults (Adult Treatment Panel III) final report. Circulation. 2002;106(25):3143-3421.

33. Rubin DB. Multiple Imputation for Nonresponse in Surveys. New York, NY: Wiley \& Sons; 1987.

34. Klein JP, Moeschberger ML. Survival Analysis: Techniques for Censored and Truncated Data. 2nd ed. New York, NY: Springer; 2003.

35. Robertson D, Oates JA. Variant angina and Raynaud's phenomenon. Lancet. 1978;1(8061):452.

36. Lewis T. Experiments relating to the peripheral mechanism involved in spasmodic arrest of circulation in fingers, a variety of Raynaud's disease. Heart. 1929;15:7-101.

37. Marasini B, Biondi ML, Mollica R, Del Santo A, Agostoni A. Cold-induced changes in plasma norepinephrine, epinephrine and dopamine concentrations in patients with Raynaud' phenomenon. Eur J Clin Chem Clin Biochem. 1991;29(2):111-114.

38. Freedman RR, Keegan D, Migály P, Galloway MP, Mayes M. Plasma catecholamines during behavioral treatments for Raynaud's disease. Psychosom Med. 1991;53(4):433-439.

39. Freedman RR, Mayes MD, Sabharwal SC. Induction of vasospastic attacks despite digital nerve block in Raynaud's siease and phenomenon. Circulation. 1989;80(4):859-862.

40. Marshall AJ, Roberts CJ, Barritt DW. Raynaud's phenomenon as side effect of beta-blockers in hypertension. Br Med J. 1976;1(6024): 1498-1499. 


\section{Supplementary materials Working definitions of RP}

Two definitions of RP were used for these analyses. The first definition was based on a method described by Maricq and Weinrich in $1988 .{ }^{1}$ This definition required subjects to have reported "blanching" or whitening of their fingers and did not depend on whether the subject experienced any cyanosis of their fingers/hands. To be classified as having RP under the narrow definition, a subject had to meet at least three of these four criteria:

1. The subject had to respond "Yes" to the question, "Are your fingers unusually sensitive to cold'?

2. The subject had to respond "Yes" to the question, "Do your fingers sometimes show unusual color changes'?

3. When shown a panel of several color pictures, the subject had to respond "Yes" to a question that asked if their hands ever looked like any of the pictures where blanching of the fingers was present. Contrasting images included a hand with edematous fingers, a hand with cyanotic fingers, and a cyanotic hand. These images appear in the article by Maricq and Weinrich. ${ }^{1}$
4. When asked "what is the palest that your fingers get?", the subject had to select either of the two most extremely pale colors from an RP skin color chart (if criteria 3 was met) or the most extremely pale color from the RP skin color chart (if criteria 3 was not met). These color charts also appear in the article by Maricq and Weinrich.

In addition to this narrow definition, we constructed a "broad" RP definition, which allowed for patients to be classified as having RP if they met the narrow definition, or if they indicated that their fingertips and/or hands ever became cyanotic. For this broad definition, subjects had to either respond "Yes" to a question that asked if their hands ever looked like any of the pictures depicting cyanosis (of the fingers or entire hand), or select the bluest or most purple color from the RP skin color chart when asked "what is the most blue (most purple) that your fingers get"?

\section{Reference}

1. Maricq HR, Weinrich MC. Diagnosis of Raynaud's phenomenon assisted by color charts. J Rheumatol. 1988;15(3):454-459.
Clinical Epidemiology

\section{Publish your work in this journal}

Clinical Epidemiology is an international, peer-reviewed, open access, online journal focusing on disease and drug epidemiology, identification of risk factors and screening procedures to develop optimal preventative initiatives and programs. Specific topics include: diagnosis, prognosis, treatment, screening, prevention, risk factor modification,

\section{Dovepress}

systematic reviews, risk \& safety of medical interventions, epidemiology \& biostatistical methods, and evaluation of guidelines, translational medicine, health policies \& economic evaluations. The manuscript management system is completely online and includes a very quick and fair peer-review system, which is all easy to use. 